\title{
Partisan Dealignment in Germany: A rejoinder to Russell Dalton
}

\author{
German Politics, accepted
}

\begin{abstract}
The work of Russell Dalton has undoubtedly played a seminal role in the study of the relation between political sophistication and partisan dealignment. We furthermore acknowledge the presence of a consensus on the occurrence of lower levels of partisanship in Germany. Using panel data as well as pooled cross-sectional observations, however, it is clear that generational replacement is not the sole driving force of partisan dealignment, but that period effects should also be taken into account. While on an aggregate level rising levels of political sophistication have occurred simultaneously with decreasing partisanship, individual level analysis suggests clearly that the least sophisticated are most likely to feel alienated from the party system. We close with some very specific suggestion on how to address the democratic consequences of declining levels of partisanship.
\end{abstract}

\section{KEYWORDS}

political sophistication, partisanship, dealignment, panel data, Germany 


\section{Introduction}

It goes without saying that the work of Russell Dalton has had a huge impact on the study of partisan dealignment and political sophistication, and indeed, in our earlier article we have acknowledged in a number of places our intellectual debt to his work. ${ }^{1}$ It is equally important to note that we agree on the fundamental trend: partisan alignment is clearly eroding in Germany and this trend will have important consequences for the future linkage mechanisms between German citizens and their political system. While not so long ago scholars still questioned the magnitude and importance of electoral change ${ }^{2}$, it is by now generally accepted in the field that the process of electoral linkage has changed structurally, and the work of Russell Dalton has played an important role in this academic debate. ${ }^{3}$

We still disagree, however, on two specific research questions. The first question is whether dealignment is mainly caused by generational replacement, or whether other elements should be taken into account as well? The second, and most fundamental question is to establish the likely consequences of dealignment: does it lead to the development of a new group of highly sophisticated apartisans ${ }^{4}$, or is there a risk of political alienation? Although we agree with many elements in the excellent article of Russell Dalton, in this rejoinder we briefly explain why we continue to disagree on these two crucial questions.

\section{Age, Period and Cohort}

There is no discussion at all about the fact that dealignment is a real trend and it affects the German political system. Both our data for the post-1992 period, as well as Dalton's data spanning the period 1972-2009 indicate a clear decline of partisanship in the German electorate. As such, both of our analyses are in line with research indicating electoral change since the late 1970s. ${ }^{5}$ Furthermore, the figures demonstrate that this trend continues throughout the most recent period as well. So on a descriptive level, there is a very broad consensus on the occurrence of partisan dealignment, as indeed Russell Dalton already stated in $1984 .^{6}$

We disagree, however, on the issue of what time effects are to be discerned underneath this aggregate-level trend towards dealignment. According to Dalton, lower levels of partisanship 
are concentrated among younger age groups, and he assumes that a process of generational replacement is driving this observation. While we agree with Dalton that using sophisticated analyses is not a goal in itself, and should not be used simply to show off statistical sophistication, correctly analysing a process of social change is notoriously difficult and it does require appropriate data and methods. The interdependence of age, periods and cohorts is one of the oldest problems in social science research and this implies that we cannot easily disentangle the three time effects using pooled cross-section data. ${ }^{7}$ In such a design, pooling several independent surveys over time, age and cohorts are basically the same. Given the complex character of this social change, we are convinced that the panel data of the SOEP that we use are superior in this regard to the cross-sectional election data Dalton uses. Indeed, panel date pose new problems with regard to panel attrition and repeated measurement, but there is no good theoretical reason to assume that being included in a panel study would have a profound effect on reporting partisan attachment.

According to Dalton, the hypothesis about generational replacement is confirmed if young people today are less partisan than an older birth cohort was at a similar age and if all age groups act in more or less the same way across time. This option, however, rules out the possibility to investigate the occurrence of period effects. Additionally, and this is more important in this context, there is no room to investigate interactions between age and period, which is an equally valid explanation for differences in the proportion of party identifiers between younger and older birth cohorts over time. As research by Dalton and others convincingly shows, young people today are indeed less partisans than their parents were at their age. ${ }^{8}$ This does not automatically imply, however, that generational replacement is the main or only mechanism that is responsible for this observed difference. An interaction between age and period effects would be an equally valid explanation. This interaction effect would imply that young people today are more strongly influenced by the general and periodic decrease in partisanship compared to older citizens. Since this group of young citizens is, unlike their parents, not yet "set in their ways" 9 by years of continuous voting experience, they are more likely to be affected by this period effect. The proportion of partisans among the generation of their parents on the other hand, might have been exceptionally high at a young age, exactly because they were living in a context of high politisation with strong partisanship. As such, the difference observed between young and older birth cohorts at a young age, should not be automatically attributed to the influence of generations or cohorts, as it could just as well be explained by an interaction between age and 
period effects. Fully understanding this complex process of social change, does require the best possible data that we have in order to document these longitudinal trends.

To illustrate his point, Dalton graphically compares the evolution of partisanship over time for different age groups (his Figure 1). In Figure 1 we replicate such a graph for the SOEP-data and hence for the shorter period 1992-2009. The graph presents the proportion of respondents identifying with a party per age group for each of the survey waves. As becomes clear from Figure 1, overall there is very little evolution over time, and additionally the gaps in proportions of partisans for different age groups as well hardly change over time. This graphical presentation of the data therefore indicates that for the period covered in our study (1992-2009) interactions between age groups and periods are minimal. The data presented by Dalton on the other hand, covering elections since 1972, first and foremost indicate strong period effects (see his Figure 1). Furthermore, his data contain indications of interactions between age groups and periods. The changes observed, however, seem to be caused mainly by a depolitisation of the youngest respondents starting in 1983 .

\section{[FIGURE 1 ABOUT HERE]}

To investigate how partisanship affects different generations, a visual representation as in Figure 2 allows for a more straightforward interpretation. In this graph, we track the proportion of partisans over time for four broad generations ${ }^{10}$, defined on the basis of their year of birth. We distinguish the pre-war generation (1910-1930), the silent generation (19311950), the civic generation (1951-1970) and generation x (1971 and later). Unlike Figure 1, this graph does indicate some change over time. Members of the youngest generation become more partisan as they grow older and acquire political experience. As such, the SOEP-data (1992-2009) provide evidence that is in contrast to the stability across time underlying the generational hypothesis. As the huge advantage of the SOEP data is that exactly the same data are observed across time, we can be convinced that the SOEP surveys are better able to capture this process of social change than the data used by Dalton.

\section{[FIGURE 2 ABOUT HERE]}

It would be a bit too easy, however, to simply say that this is a difference of data, and that different data sources simply tell a different story. Therefore, we have tackled the problem 
head on, by using exactly the same data as Dalton, for the entire period 1972-2009. ${ }^{11}$ Even more strongly so than for the shorter period covered by the SOEP-data, Figure 3 indicates the presence of strong period effects, especially in the period between 1975 and 2000. In contrast to the assumption of relative stability within generations, the figures indicate a decline of partisanship among all generations. For all generations we furthermore observe the same period effects. This graph, using the very same data as Dalton is relying on, questions the ass umption of generational change. Looking at patterns of change in this way, therefore, our and Dalton's data hint in the same direction: all age groups and all cohorts have witnessed a dramatic erosion of partisanship. The fact that the SOEP-data suffer from attrition problems and the fact that our analyses included respondents from East and from West is therefore unlikely to be causing serious distortions.

\section{[FIGURE 3 ABOUT HERE]}

Our claim therefore quite strongly remains that the decline of partisanship cannot be solely attributed to cohort effects or generational replacement. ${ }^{12}$ These visual assessments and the fact that age, period and cohort are linearly dependent, have led us in our original article to a focus on age and period effects only. Generational effects are then controlled for by means of proxy variables that are likely to be associated to these processes of generational change. ${ }^{13}$ This is the reason for the inclusion of variables as religious denomination and trade union membership. In this sense, Dalton is absolutely right in pointing out that controlling for these factors might explain generational patterns as new age cohorts are e.g. less religious than previous cohorts. Given the fact that age, period and cohort are linearly dependent, including these proxies for generations is our approach to investigate the impact of these three timerelated variables in a single analysis. Our conclusion therefore does remain that while it is likely that cohort mechanisms play a role, it is just as important to assess the contribution of period and age effects to this process of social change. While Dalton states that our research design prevents us from seeing the forest through the trees, our claim does remain that carefully studying trees gives insights on what kind of forest you are taking about. And indeed, following exactly the same tree, or respondent, over a longer period of time, which is what panel research is there for, is the very best way to investigate social change.

\section{Sophistication or alienation?}


Our discussion with Dalton, however, is not only based on questions of data and methods of analysis, but it also has implications for the much more important point of how the future of democratic electoral politics in Germany, and in liberal democracies in general looks like. While Dalton assumes that rising political sophistication contributes to electoral dealignment, our analyses suggest the contrary, and hint at a risk for political alienation.

As is pointed out by Dalton, one has to take into account processes of change when investigating the causes and correlates of partisanship. This is essential, because it is indeed possible and even very likely that "the characteristics of independents have changed as their numbers have expanded". ${ }^{14}$ It is right, therefore, to point out that investigating individuallevel correlations between political interest or education and partisanship does not suffice to document these changes. Given that the characteristics that are typically associated with partisanship might have changed over time, interactions between these characteristics and time have to be investigated. This is exactly what our analyses on the SOEP-data provide. As a consequence, our findings not only indicate that high levels of education and high levels of interest in politics are associated with partisanship. Our results furthermore point out the link between these characteristics and party identification grows stronger between 1992 and 2009, as evident from the significant interactions with the survey year.

The fact that panel-data are to be preferred for investigating age, period and cohort effects, has led us to rely on the SOEP-data. As a consequence, our analyses cover dealignment in Germany since 1992 only. One could obviously argue that the broad patterns of change in partisanship and shifts within the electorate have already occurred earlier and that the finding that partisanship is now more strongly associated with high levels of political sophistication holds for the most recent period only. In order to investigate whether these patterns are robust when investigating a longer period of time, we replicated the analyses for the pooled crosssectional data of German Elections Studies and Politbarometer surveys used by Dalton as well. ${ }^{15}$ Doing so, we can gain insights in changes in the correlates of partisanship since 1976.

As holds for our investigation of partisanship by means of the SOEP-data, the analyses take the form of multivariate logistic regressions. The dependent variable is partisanship, and the question wording for this item is identical for both datasets. In line with the analyses on the SOEP-panel, as a first step, we present three models in Table 1. 
Model 1 includes the main and squared effects of age ${ }^{16}$ and survey year. Furthermore, the socio-demographic determinants gender, educational leve $1^{17}$ and religious denomination ${ }^{18}$ are included. ${ }^{19}$ For this analysis, only respondents from the Western Länder are included. In line with what the analyses on the SOEP-data pointed out, growing older, being male, being higher educated and having a Catholic or Protestant denomination all significantly increase the probability of identifying with a political party.

In Model 2 interactions between the socio-demographic variables and election years are included. These interaction terms allow assessing whether the impact of these variables on having a party identification changes over the period 1976-2009. First, we observe a significant interaction between age and election year, indicating an over-time increase of the positive effect of age on partisanship. Furthermore, the effect of gender is diminishing. Most importantly, however, we can observe an increase of the effect of being higher educated on identifying with a party. As a consequence, the educational gap between partisans and nonpartisans observed in Model 1 seems to be increasing over time.

The next model (Model 3 in Table 1) additionally includes political interest ${ }^{20}$ and its interactions with election year and education. As clear from the results, the middle interested are significantly more likely to identify with a party compared to the low interested and the high interested even more so. For the full period covered by these data (1976-2009), therefore, it is safe to conclude that partisanship is associated with high levels of political interest. Furthermore, allowing changing effects by means of interactions with time, indicates that the effect of political interest increases over time. This interaction effect and the robust significant interaction effect of higher education and time indicate a strengthening of the link between being highly politically sophisticated and identifying with a political party. Unlike what Dalton claims, therefore, and in contrast to what aggregate-level trends seem to suggest, the politically sophisticated are more likely to identify with a party and even more so now than was the case a number of decades ago.

\section{[TABLE 1 ABOUT HERE]}

The results of Model 4 furthermore indicate that the differences observed between the aggregate-level evidence presented by Dalton (his Table 2) and our multivariate analyses are not due to differences in operationalizations either. In this model, rather than including 
education and political interest and their interactions with time separately, we rely on an index of cognitive mobilization. This index replicates how Dalton operationalizes cognitive mobilization, combining political interest and levels of education. ${ }^{21}$ The results of this analysis as well indicate that cognitive mobilization increases the likelihood of identifying with a party (the significant and positive main effect) and even more so as time proceeds (the significant and positive interaction effect with time).

Despite some differences in directions and significance levels of the predictors of partisanship, the main conclusion of our analysis on the SOEP-data holds for the data used by Dalton as well. Being higher educated and being highly interested in politics significantly increase the probability of being a partisan. Furthermore and more importantly, these effects grow stronger over time. As a consequence, both datasets provide indications that the gap in political sophistication between partisans and apartisans is increasing over time. Neither a reliance on panel-data or the inclusion of citizens living in the East of Germany, nor a focus on the most recent period only can therefore explain differences between our conclusion and Dalton's interpretation. The only difference left is therefore that Dalton looks at trends at the aggregate level, while we try to disentangle individual-level mechanisms. At a societal level, there is no doubt that rising education and decreasing partisanship have occurred simultaneously. This aggregate level observation, however, does not yet lead to any insights on individual level mechanisms. Despite these broad social changes, it is still possible that especially the least politically sophisticated are most strongly affected by processes of partisan dealignment.

\section{Discussion}

In this rejoinder, we have taken up some of the thought-provoking ideas of Russell Dalton. First of all, we have shown that, no matter what kind of data are being used, and what kind of method of analysis is relied on, it is clear that cohort effects are not the sole factor driving the process of dealignment. This is an important insight, as it allows us to depart from the outlook on value change in political science, that has dominated this field ever since Inglehart first put forward the generational replacement idea now more than four decades ago. While of course it has to be acknowledged that cohorts differ, we should also pay more attention to period effects. This is also very important in order to determine our future research strategy. The 
claim about generational replacement is intuitively attractive, because it leads to an almost deterministic view on social and political change. The only thing scholars and decision makers have to do is to lean back and wait until new age cohorts have arrived, and this will lead to societal change. The fact that period effects might be equally important, however, forces us to think about what kind of factors are responsible for these period effects. Specific elements of the political system, or the party system might have changed, with as a result different linkage systems between citizens and the political system. This kind of period effects should receive more attention in future research.

Most fundamentally, however, we disagree about the relation between political sophistication and partisan dealignment. This is of crucial importance. To put it all too simple: if there is a positive relation, we should not worry at all about dealignment. In that case, the most enlightened and best informed citizens indeed will try to make an informed party choice, and this should force political parties to respond more sharply to the preferences of the population. In that case, dealignment would be something positive from the point of view of democratic accountability and result in the rise of ideal-type democracies. Most likely, this process is taking place in a two party-system like the United States where there are few viable alternatives than becoming apartisans for sophisticated voters who do not identify with one of the two major parties. But in multiparty systems, voters have more options so that even highly sophisticated voters are quite likely to find a political party that corresponds closely to their own political preferences. We agree with Dalton in noticing that one of the most profound changes in Western societies during the past decades has been the rise of education levels, and hence the rise in political sophistication. As simultaneously partisan alignment has decreased, it is only natural to assume a relation between both processes. Our individual level data, however, suggest otherwise: it are the least politically sophisticated who are likely to feel alienated from the party system.

To end on a constructive note: we also have to acknowledge some limitiations of this kind of research on partisanship. We could go on confronting research methods and methods of analysis, but this is probably not the best way forward for political science. Basically our predictions are different. If Dalton is right (and we have to acknowledge that he has been right so often during the past decades), the apartisans should be sophisticated, and therefore their party preference should rely on 'sophisticated' considerations, like ideology, party programs, individual preferences, strategic voting, and adequate political information. If all these kind of 
voting motives do replace the traditional role of partisan identity in the vote choice process, we will have to agree with Dalton that our electoral process has been enriched and will lead to more democratic accountability. If, on the other hand, apartisanship and electoral volatility are concentrated among the least sophisticated, we would expect voting motives like media and campaign effects and politicians' personality to become ever more important. The study of voting motives and volatility therefore, would allow gaining new insights into the question what are the real determinants and consequences of partisan dealignment. This is an important question because of its implication for the future of democracy. We fully agree with Dalton: partisanship has declined as a voting motive. The question that remains however is: what has replaced partisanship? Is it a sophisticated assessment of party positions? Or is it a superficial reliance on media and personality effects? Answering this empirical question should shed more light on the difference between the position of Russell Dalton and our own position. 
Figure 1. Proportion of party identifiers by age group (SOEP, 1992-2009)

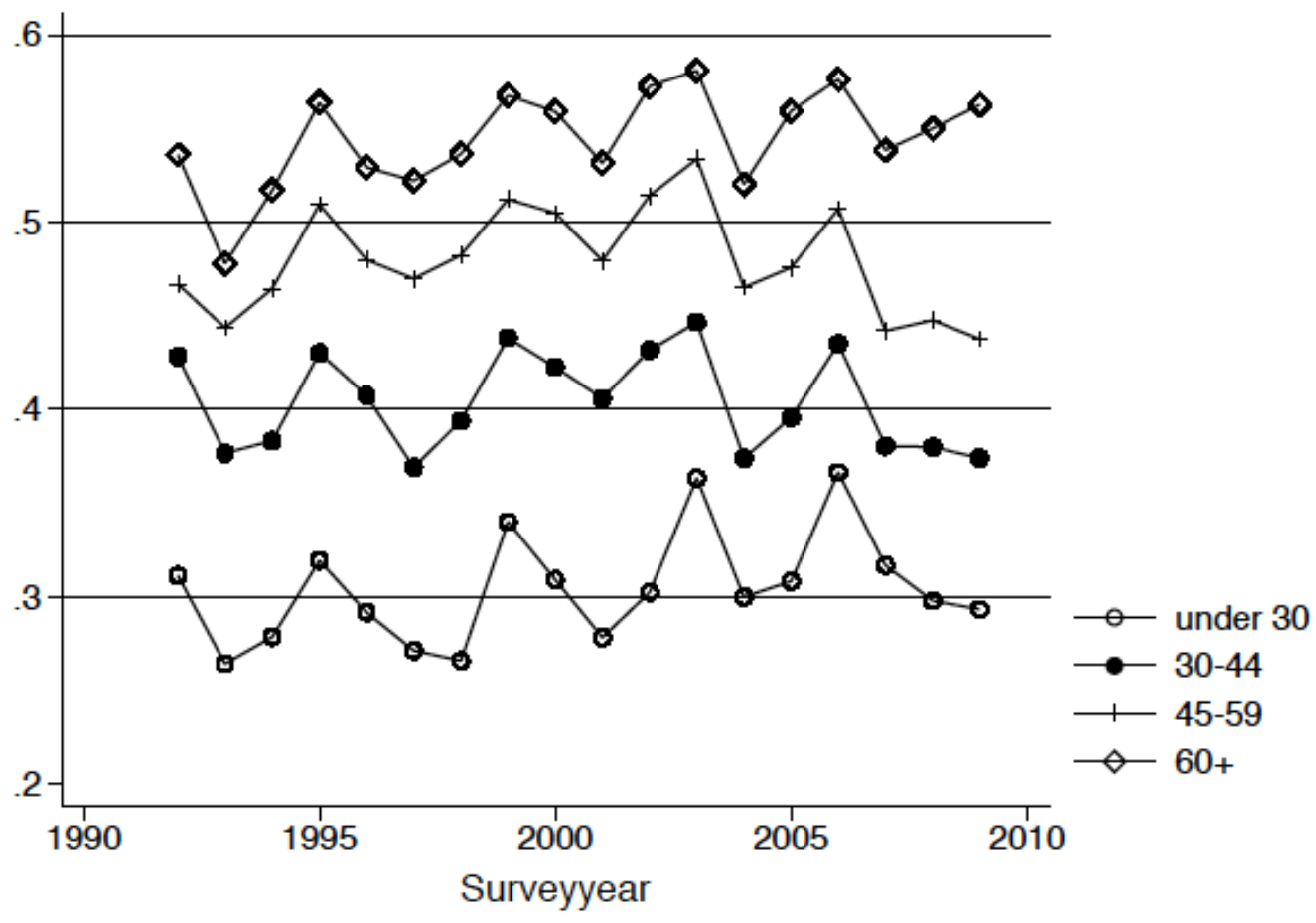

Figure 2. . Proportion of party identifiers by generation (SOEP, 1992-2009)

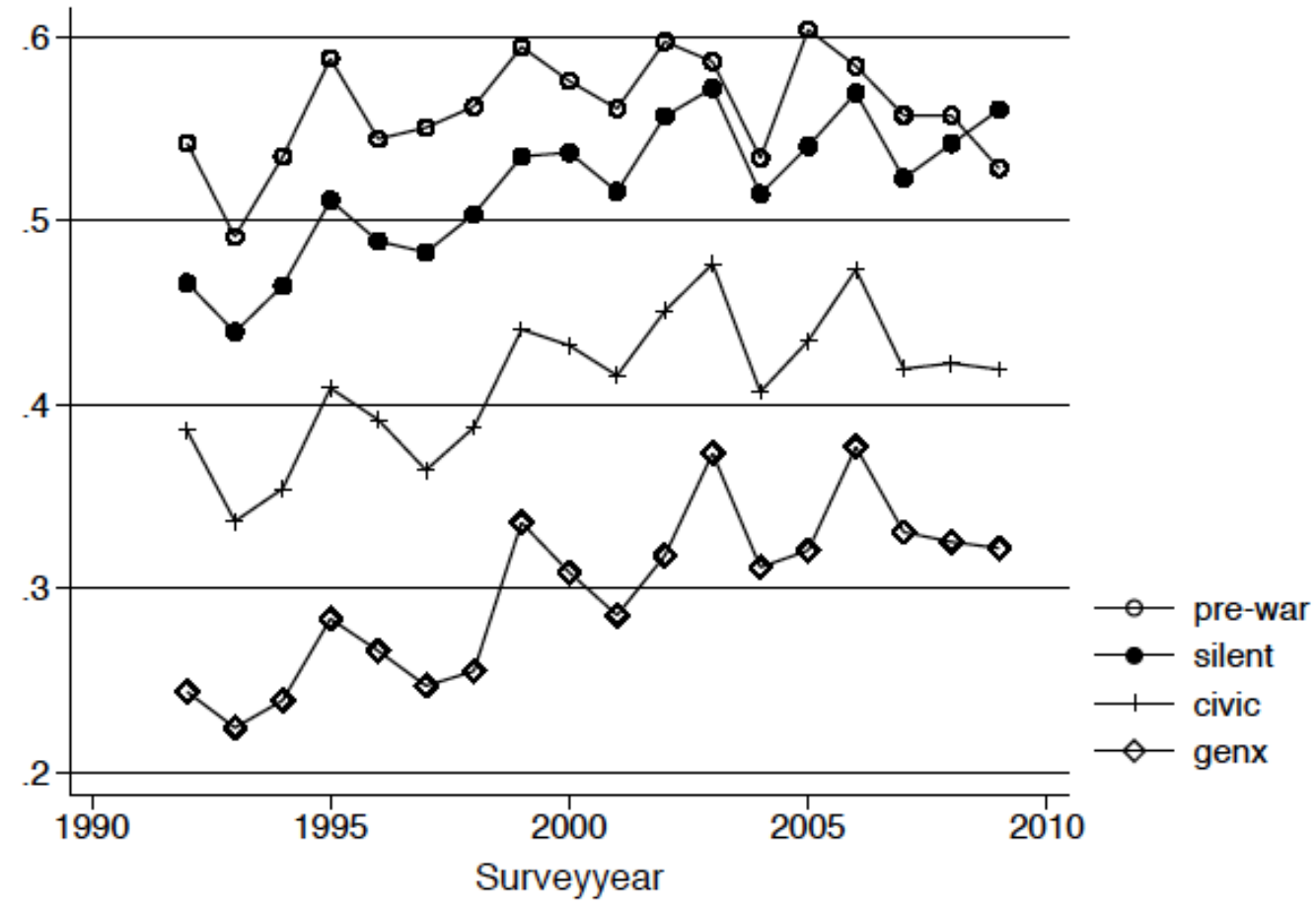


Figure 3. Proportion of party identifiers by generation (GES and Politbarometer, 19722009)

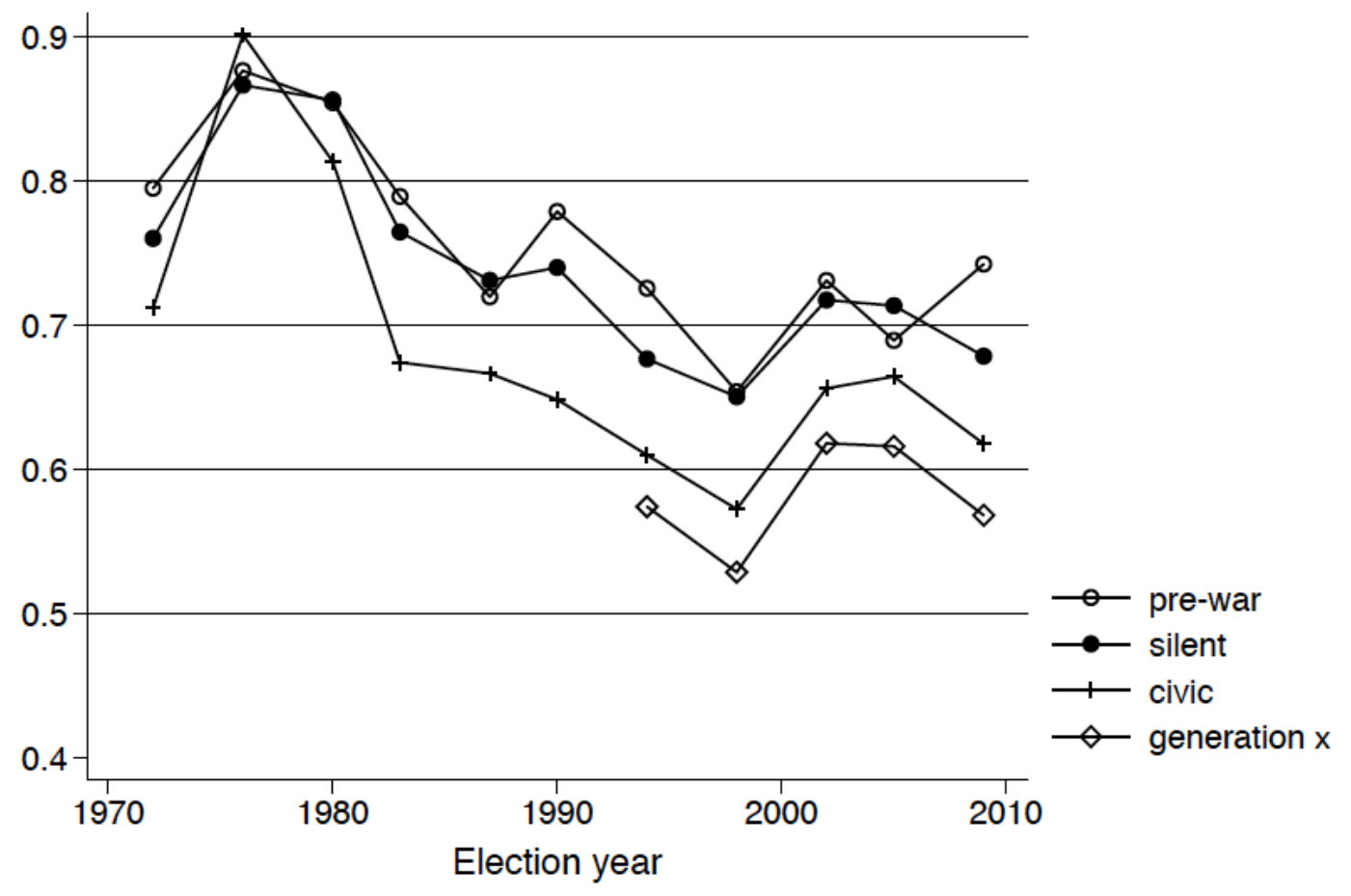


Table 1. Explaining party identification (GES and Politbarometer data, 1976-2009)

\begin{tabular}{|c|c|c|c|c|}
\hline & $\begin{array}{l}\text { Model 1 } \\
\text { B (SE) Sig }\end{array}$ & $\begin{array}{c}\text { Model 2 } \\
\text { B (SE) Sig. }\end{array}$ & $\begin{array}{l}\text { Model 3 } \\
\text { B (SE) Sig. }\end{array}$ & $\begin{array}{c}\text { Model } 4 \\
\text { B (SE) Sig. }\end{array}$ \\
\hline Age & $0.033(0.012) * *$ & $0.019(0.015) \mathrm{ns}$ & $0.011(0.014) \mathrm{ns}$ & $0.019(0.016) \mathrm{ns}$ \\
\hline $\mathrm{Age}^{2}$ & $-0.000(0.000) \mathrm{ns}$ & $-0.000(0.002) \mathrm{ns}$ & $-0.000(0.000) \mathrm{ns}$ & $-0.000(0.000) \mathrm{ns}$ \\
\hline Election year & $-0.093(0.018) * * *$ & $-0.110(0.019) * * *$ & $-0.128(0.018) * * *$ & $-0.108(0.018) * * *$ \\
\hline Election year ${ }^{2}$ & $0.001(0.000) * *$ & $0.001(0.000) * *$ & $0.002(0.000) * *$ & $0.001(0.000) * *$ \\
\hline Age*Election year & & $0.001(0.000) * * *$ & $0.000(0.000) * * *$ & $0.000(0.000) * * *$ \\
\hline Male & $0.105(0.043) *$ & $0.383(0.083) * * *$ & $0.201(0.084) *$ & $0.334(0.088) * * *$ \\
\hline Male*Election year & & $-0.011(0.003) * * *$ & $-0.009(0.003) * *$ & $-0.011(0.003) * * *$ \\
\hline \multicolumn{5}{|l|}{ Education (ref: Middle) } \\
\hline Low & $-0.200(0.044) * * *$ & $-0.243(0.142) \mathrm{ns}$ & $-0.025(0.158) \mathrm{ns}$ & \\
\hline High & $0.240(0.068) * * *$ & $-0.348(0.122) * *$ & $-0.290(0.149) \mathrm{ns}$ & \\
\hline Low*Election year & & $0.001(0.005) \mathrm{ns}$ & $0.004(0.005) \mathrm{ns}$ & \\
\hline High*Election year & & $0.022(0.004) * * *$ & $0.026(0.005) * * *$ & \\
\hline \multicolumn{5}{|l|}{$\begin{array}{l}\text { Religious denomination (ref: } \\
\text { other/none) }\end{array}$} \\
\hline Catholic & $0.217(0.035) * * *$ & $0.266(0.189) \mathrm{ns}$ & $0.350(0.174) *$ & $0.319(0.194) \mathrm{ns}$ \\
\hline Protestant & $0.188(0.023) * * *$ & $0.122(0.096) \mathrm{ns}$ & $0.164(0.089) \mathrm{ns}$ & $0.170(0.098) \mathrm{ns}$ \\
\hline Catholic*Election year & & $-0.002(0.006) \mathrm{ns}$ & $-0.005(0.006) \mathrm{ns}$ & $-0.003(0.006) \mathrm{ns}$ \\
\hline Protestant*Election year & & $0.003(0.003) \mathrm{ns}$ & $0.001(0.003) \mathrm{ns}$ & $0.001(0.003) \mathrm{ns}$ \\
\hline \multicolumn{5}{|l|}{ Political interest (ref: low) } \\
\hline Middle & & & $0.437(0.097) * * *$ & \\
\hline High & & & $1.018(0.056) * * *$ & \\
\hline Middle interest*Election year & & & $0.013(0.003) * * *$ & \\
\hline High interest*Election year & & & $0.011(0.002) * * *$ & \\
\hline Political interest*Low education & & & $-0.133(0.044) * *$ & \\
\hline Political interest*High education & & & $-0.207(0.030) * * *$ & \\
\hline High cognitively mobilized (ref: low) & & & & $0.401(0.096) * * *$ \\
\hline $\begin{array}{l}\text { High cognitively mobilized*Election } \\
\text { year }\end{array}$ & & & & $0.008(0.003) *$ \\
\hline Constant & $0.732(0.200) * * *$ & $1.270(0.319) * * *$ & $1.064(0.294) * * *$ & $0.957(0.345) * *$ \\
\hline Log likelihood & $-12,334.040$ & $12,304.344$ & $-12,055.170$ & $-12,204.954$ \\
\hline Pseudo- $\mathrm{R}^{2}$ & 0.036 & 0.038 & 0.058 & 0.046 \\
\hline
\end{tabular}




\section{Endnotes}

${ }^{1}$ R. Dassonneville, M. Hooghe and B. Vanhoutte, 'Age, Period and Cohort Effects in the Decline of Party Identification in Germany: An Analysis of a Two Decade Panel Study in Germany (1992-2009)', German Politics 21/2 (2012), pp. 209-227.

2 P. Mair, 'Myths of Electoral Change and the Survival of Traditional Parties', European Journal of Political Research 24/2 (1993), pp. 121-133.

${ }^{3}$ R.J. Dalton and M.P. Wattenberg (eds), Parties without Partisans. Political Change in Advanced Industrial Democracies (Oxford: Oxford University Press, 2000) ; M.N. Franklin, T. Mackie and H. Valen (eds), Electoral Change. Responses to Evolving Social and Attitudinal Structures in Western Countries (Colchester, ECPR Press, 2009); P. Mair 'Democracy Beyond Parties' (Irvine: Center for the Study of Democracy, 2005).

${ }^{4}$ J.J. Albright, 'Does Political Knowledge Erode Party Attachments? A Review of the Cognitive Mobilization Thesis', Electoral Studies 28/2 (2009), pp. 248-260; S. Marthaler, 'The Paradox of the Politically Sophisticated Partisan: The French Case', West European Politics 31/5 (2008), pp. 937-959.

${ }^{5}$ H. Clarke and M. Stewart, 'The Decline of Parties in the Minds ofCitizens', Annual Review of Political Science 1 (1998), pp. 357-378; I. Crewe, B. Särlvik and J. Alt, 'Partisan Dealignment in Britain 1964-1974', British Journal of Political Science 7/2 (1977), pp. 129190; M. Pedersen, 'The Dynamics of European Party Systems: Changing Patterns of Electoral Volatility', European Journal of Political Research 2/1 (1979), pp. 1-26.

${ }^{6}$ R.J. Dalton, 'Cognitive Mobilization and Partisan Dealignment in Advanced Industrial Democracies', Journal of Politics 46/1 (1984), pp. 264-284.

${ }^{7}$ See for example: N.D. Glenn, Cohort Analysis (Beverly Hills: Sage, 1977); D. Knoke and M. Hout, 'Reply to Glenn', American Sociological Review 41/5 (1976), pp. 905-908; K. O. Mason, W.M Mason, H.H. Winsborough and K.W. Poole, 'Some Methodological Issues in Cohort analysis of Archival Data', American Sociological Review 38/2 (1973), pp. 242-258; R. O'Brien, 'The Age-Period-Cohort Conundrum as Two Fundamental Problems', Quality \& Quantity 45/6 (2011), pp. 1429-1444; W.I. Rodgers, 'Estimable Functions of Age, Period, and Cohort Effects', American Sociological Review 47/6 (1982), pp. 774-787.

${ }^{8}$ P.A. Beck, 'A Socialization Theory of Partisan Realignment', in R. Niemi et al (eds), The Politics of Future Citizens (San Francisco: Jossey Bass, 1974); R.J. Dalton, 'Cognitive Mobilization and Partisan Dealignment in Advanced Industrial Democracies', Journal of Politics 46/2 (1984), pp. 264-284; J.R. Tilley, 'Party Identification in Britain: Does Length of Time in the Electorate Affect Strength of Partisanship?', British Journal of Political Science 33/2, pp. 332-344.

${ }^{9}$ M. Franklin, Voter Turnout and the Dynamics of Electoral Competition in Established Democracies since 1945 (New York: Cambridge University Press, 2004), p. 216.

${ }^{10}$ Generations here are understood as defined by Mannheim; a birth cohort or group of cohorts that lived through the same events and is therefore influenced by these events. See: K. Mannheim, 'Das Problem der Generationen', Kölner Vierteljahrshefte fur Soziologie 7/2, pp. 157-185, 309-330.

${ }^{11}$ Following Dalton, we pooled the data from the 1972 German Election Study (S0635), the 1976 German Election Study (S0823), the 1980 German Election Study (S1053) and Politbarometer surveys for elections from 1983 to 2009. Further following Dalton, for the Politbarometer data we included surveys for the election month, the month before the election and the month after the election. 
12 P.R. Abramson, 'Generational Change and the Decline of Party Identification in America, 1952-1974', American Political Science Review 70, pp. 469-478; W. van der Brug and S. Kritzinger, 'Generational Differences in Electoral Behavior', Electoral Studies 31/2, pp. 245249.

${ }^{13}$ Rodgers, 'Estimable Functions of Age, Period, and Cohort Effects'.

${ }^{14}$ Dalton, 'Interpreting Partisan Dealignment in Germany'.

${ }^{15}$ No information on political interest was available for the selected data of 1990 and 2005, these elections are therefore not included in the pooled dataset.

${ }^{16}$ Given that age is measured in broad categories in the Politbarometer surveys, the lower bounds of these categories are included in the analyses.

${ }_{17}$ Distinguishing the lower educated (without degree or only a Hauptschule degree), the middle educated (Mittlere Reife) and higher educated (Abitur and more).

${ }^{18}$ Distinguishing Catholic respondents, Protestant respondents and respondents with another or no religious denomination.

${ }^{19}$ Information on trade union membership is not included in this pooled dataset.

${ }^{20}$ Using the categories little interest, some interest and strong interest employed by Dalton as well.

${ }^{21}$ Both on a 0-2 scale, subsequently summed. Tho se who score 3 or 4 on this combined index are considered high cognitively mobilized. 